\title{
Comparative Experiments on Mouse-based and Typing-based Copy-and-Paste Methods
}

\author{
Hiroyuki Mitsuhara*, Masami Shishibori*, Akihiro Kashihara**
}

(Received 7 June 2017 and accepted in revised form 30 November 2017)

\begin{abstract}
Comparative experiments about two copy-and-paste methods, i.e., mouse-based and typing-based methods, were conducted to clarify the effects of the methods. The experiments were conducted for a period of five years with graduate students in the context of an investigative report writing assignment and they were focused on a recall test as the primary survey method. The experimental results demonstrated that the typing-based method imposes a burden on students and reduces report writing efficiency; however, it is more effective for information memorization than the mouse-based method.
\end{abstract}

Keywords: copy and paste, information memorization, investigative report writing, plagiarism, recall test, web

\section{Introduction}

The web has become an indispensable source of information, and in educational institutions (e.g., universities), students often use the web as their main information source when writing investigative reports. However, students may plagiarize information found on the web, i.e., copy and paste texts and images from web pages. Plagiarized reports are recognized as a social problem $^{(1,2)}$ and various countermeasures have been proposed $^{(3,4)}$. Web page plagiarism can violate copyrights. In addition, students may not learn effectively, i.e., ineffective knowledge construction. Students who copy and paste without scrutinizing the information they obtain from web pages are likely to write superficial reports. Therefore, it is imperative that web page plagiarism be eliminated.

We have developed an investigative report writing support system that prevents web page plagiarism by restricting copy-and-paste operations ${ }^{(5)}$. The system, called ReNote, enables students to take digital notes (saved in Rich Text format) while comparing web pages and then write reports based on their digital notes. The system forces students to type digital notes. In other words, if students wish to copy text from a web page, they must type the text verbatim. This will restrict the amount of text that is copied verbatim and will encourage students to construct their own notes and write

\footnotetext{
*Graduate School of Technology, Industrial and Social Sciences, Tokushima University, Japan

**Graduate School of Informatics and Engineering, The University of Electro-Communications, Japan
}

reports based on their own ideas (i.e., constructed knowledge through comparing web pages and digital notes). In fact, we have previously reported on an experiment which showed that the system has possible beneficial effects for effective knowledge construction, compared with usual investigative report writing methods allowing copy and paste ${ }^{(6)}$.

On the other hand, there are benefits on copy and paste in investigative report writing. For example, collecting initial information from the web becomes more efficient. Copy and paste can also be regarded as meaningful knowledge construction activities that entail absorbing, consolidating, and assimilating concepts ${ }^{(7)}$. It is true that restricting copy-and-paste operations will result in lowered efficiency. Thus, how to deal with copy and paste represents dealing with a trade-off between effectiveness and efficiency.

We assume that there are two copy-and-paste methods, i.e., mouse-based and typing-based. It is intuitive to assume that the typing-based method will have higher learning effects for investigative report writing. In ReNote, the typing-based method is not encouraged, but concurrently not prevented; students can copy and paste text from web pages by typing the text verbatim into their digital notes. Even if students rely on the typingbased method, they are expected to construct knowledge to some extent. Thus, we focus on the learning effects of the two copy-and-paste methods. In other words, our research question is to clarify which method is more effective.

Typing is a primary activity in contemporary learning environments. For example, digital note-taking is 
becoming a common activity in "bring your own device" classes ${ }^{(8)}$ and has attracted attention as a research topic. However, studies about digital note-taking have shown diverse results. Mueller and Oppenheimer ${ }^{(9)}$ demonstrated that note-taking in longhand is more effective relative to recall tests than typing-based digital note-taking on laptops, which facilitates verbatim transcription of lecture content. Bui et al. ${ }^{(10)}$ reported that digital note-taking to transcribe and organize lecture content is effective for immediate and delayed recall tests, respectively. Experimental results may be inconsistent under different conditions (e.g., participants, tools, and note-taking strategies). However, we think that verbatim transcription, i.e., a specific type of copy and paste, is a definitive factor for successful recall.

In this context, we conducted comparative experiments for a period of five years with graduate students in the context of an investigative report writing assignment in an actual course. In particular, we focused on recall tests to examine the effectiveness of both copyand-paste methods by evaluating the influence of these methods on student recall of expository text (i.e., factual knowledge) on a web page.

The remainder of this paper is organized as follows. Section 2 presents an overview of an investigative report writing model to clarify the need for recall tests. Section 3 introduces related work focusing on both digital note-taking as well as the copy-and-paste methods. Section 4 details comparative experiments and provides results and considerations. Finally, Section 5 summarizes this study and gives suggestions for future work.

\section{Information Memorization in Inves- tigative Report Writing}

In this study, we defined the achievement objective of investigative report writing using the web as follows: "students collect and understand many facts (term explanations) that comprise a report topic." Such report writing can be considered as knowledge construction that requires students to browse a large number of web pages. Previously, we proposed an investigative report writing model that consists of four activities, i.e., web browsing, note-taking, report writing, and reflection ${ }^{(11)}$. Concurrently, we proposed a knowledge construction model that divides web browsing into "information comparison" and "knowledge application" activities ${ }^{(12)}$.
These two activities require at least two web pages.

To narrow our research focus, we prioritized "information memorization" over information comparison in the knowledge construction model. Information memorization means that students read and memorize expository text and images from a web page. When students desire a steady rate of information memorization, they will record the information by a method that is between reading and memorizing. This recording method is hereafter referred to as "copy and paste." We considered information memorization as the initial activity for investigative report writing. Generally, the information recorded by this method is not constructed knowledge; however, it is a primary source for subsequent knowledge construction. In addition, this information is retained separately from the constructed knowledge created after the students complete the investigative report writing. If students retain the memorized information, they will be able to construct or revise knowledge from the recalled information. Students who consider investigative report writing to be of negligible importance may proceed to write reports without (digital) note-taking, which should be performed after completing information comparison and knowledge application. Further, these students copy the relevant information within a single web page and paste it into their report. In the worst-case scenario, these students may not even attempt to memorize the information.

In this study, we investigated whether mouse-based

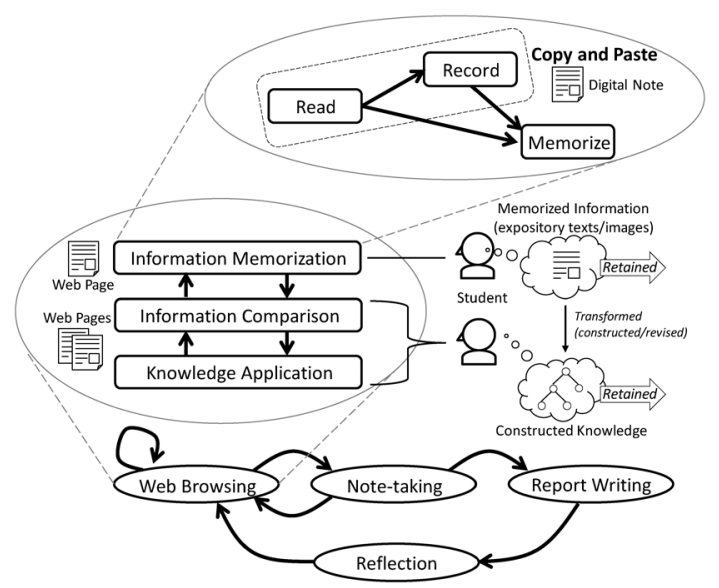

Figure 1. Revised Investigative Report Writing Model. 
and typing-based copy-and-paste methods result in information memorization. We focused on information memorization of expository text because text may be memorized more frequently than images in knowledge construction. In other words, we focused on recalling expository text. Figure 1 shows an overview of the revised investigative report writing model.

\section{Related Work}

Many previous studies have examined note-taking, which entails cognitive efforts such as encoding (i.e., writing while hearing, observing, selecting, rephrasing, and organizing information $)^{(13,14)}$. The cognitive efforts (process) lead to comprehension, and the observed notes (product) can be used to review information. For example, King ${ }^{(15)}$ investigated and compared the efficiency of college students in three different learning activities (i.e., self-questioning, summarizing, and note-takingreview) after note-taking using both immediate as well as retention tests. King determined that summarizers and self-questioners recalled more lecture content as compared to notetaking-reviewers in both the tests.

In addition to traditional note-taking, studies on digital note-taking have been conducted. For example, Wei et al. ${ }^{(16)}$ focused on college students who multitasked by taking notes and simultaneously participating in online chatting during lectures. These types of notetakers were observed to recall lecture content with considerably less accuracy as compared to those who did not multitask. Beck ${ }^{(17)}$ sought to verify the previous findings ${ }^{(10)}$ that digital note-taking was superior to traditional note-taking (i.e., taking written notes); however, both the results of immediate and delayed tests were in conflict for this hypothesis. The effectiveness of digital note-taking may therefore be sensitive to diverse conditions.

Although copy and paste (i.e., using a mouse to copy text and paste something into a notes document) is generally considered to be an inferior digital note-taking method, it is one of the most frequently used methods ${ }^{(18)}$. Several experiments have been conducted to compare typing-based and copy-and-paste-based note-taking. Katayama et al. ${ }^{(19)}$ conducted recall tests one week after a note-taking task and concluded that typing-based notetaking led to higher knowledge retention. As far as notetaking from web pages was concerned, Igo et al. ${ }^{(20)}$ focused on two copy-and-paste methods (restricted and unrestricted) for a specific, table-based note-taking tool and conducted four types of recall tests. These results indicated that the restricted method was significantly effective in terms of deeper processing and restrictive decision making. Bauer and Koedinger ${ }^{(21-23)}$ conducted a few experiments targeting university students to develop digital note-taking tools and observed that copy-andpaste-based note-taking was more efficient than typingbased note-taking. However, the copy-and-paste method significantly reduced attention and learning, which was demonstrated by the fact that students retained less information after a week. In addition, the notes taken using the copy-and-paste method were wordier.

Further, this study aimed at predicting the effectiveness of copy-and-paste methods through experiments, but it differed from already existing studies because a one-off recall test was conducted at longer intervals of time, i.e., approximately one month, in different years. Experimental results such as these have never been presented before this study was conceived. Therefore, this study can provide new experimental results in the domain of digital note-taking.

\section{Experiments}

It should be noted that our research question stemmed from a study of web page plagiarism in investigative report writing. To clarify the effects of the two copy-and-paste methods, we conducted comparative experiments where participants wrote investigative reports using the web as an information source. In our experiments, we focused on unexpected investigative report writing and purposefully forced students to copy and paste information within a single web page into their report.

\subsection{Conditions}

We think that investigative report writing varies considerably among students due to the different choices that the students make (e.g., tools and strategies). Except for the copy-and-paste method, it is difficult to unify experimental conditions such that participants can write reports in a familiar manner. In addition, the experiments should not entail extraordinary tasks or external monitoring that could influence report writing. Ideally, participants should not be aware that they are participating in an experiment. However, it is difficult to 


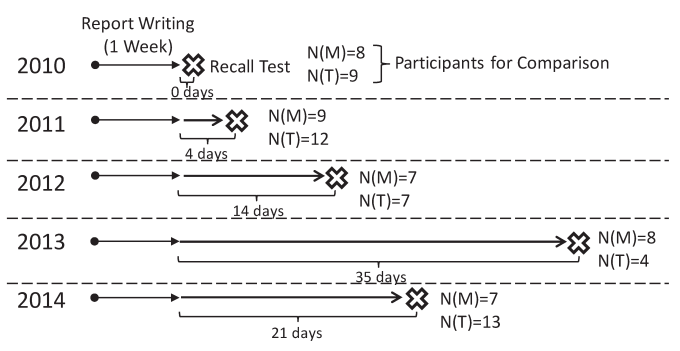

Figure 2. Experimental Procedure.

collect and interpret results if the conditions are completely uncontrolled.

By attaching importance to typical investigative report writing, we determined the following experimental conditions: (1) participants could use their personal computers and familiar applications (i.e., web browsers and word processors) and (2) the investigative report writing was assigned in an actual master's degree level course.

\subsection{Procedure}

We adopted recall tests as the main survey method. Frequently, recall tests are conducted after an interval of hours or days. We attempted to clarify the effect of different intervals. However, multiple recall tests should be avoided because the results may be influenced by the previous test. Thus, we conducted a one-off recall test at different intervals in different years. In other words, we conducted a recall test once a year for five years (2010 to 2014). Figure 2 summarizes the experimental procedure.

\subsubsection{Participants}

The participants were Japanese information science graduate students who were taking an educational technology course. The number of participants varied annually. Analysis of variance (ANOVA) revealed no significant difference among the academic scores of the participants over five years $(F(9,71)=0.96, n$.s. $)$. The participants were accustomed to writing investigative reports using the web as the primary information source.

In a mid-term educational technology class that focused on web-based learning ("Consider a versatile model of knowledge construction from the web."), the participants were assigned an investigative report writing task and randomly divided into two groups each
Table 1. Final Group Composition.

\begin{tabular}{|c|c|c|r|r|r|c|}
\hline \multirow{2}{*}{ Year } & \multirow{2}{*}{$\begin{array}{c}\text { Interval } \\
\text { (days) }\end{array}$} & \multicolumn{2}{|c|}{$N$ (participants) } & \multicolumn{3}{|c|}{ Mean remaining time (min) } \\
\cline { 3 - 7 } & $\mathrm{M}$ & $\mathrm{T}$ & $\mathrm{M}$ & $\mathrm{T}$ & $p$ (t-test) \\
\hline \hline 2010 & 0 & 8 & 9 & 4,910 & 4,702 & 0.914 \\
\hline 2011 & 4 & 9 & 12 & 11,295 & 8,541 & 0.065 \\
\hline 2012 & 14 & 7 & 7 & 23,382 & 22,330 & 0.458 \\
\hline 2013 & 35 & 8 & 4 & 54,785 & 56,831 & 0.461 \\
\hline 2014 & 21 & 7 & 13 & 34,951 & 33,035 & 0.293 \\
\hline
\end{tabular}

M, Mouse-based; T, Typing-based

using one of the copy-and-paste methods, i.e., mousebased (group M) and typing-based (group T) (Table 1).

\subsubsection{Assignment}

An investigative report writing assignment should focus on an unfamiliar topic that prompts students to investigate it. In the context of academic classes, this unfamiliar topic could be anything ranging from an advanced academic topic to a peripheral topic. Red tides were chosen as the topic for our experiments because it could be investigated using the Internet and the majority of our participants were both interested in as well as unfamiliar with red tides. A Japanese Wikipedia page describing red tide (https://ja.wikipedia.org/wiki/\%E8\% $\mathrm{B} 5 \% \mathrm{~A} 4 \% \mathrm{E} 6 \% \mathrm{BD} \% \mathrm{AE})$ was designated as the only information source, and the internal subtopic "Causes" was designated as the copy-and-paste target (approximately 500 characters). In addition, participants were requested to read the expository text carefully and complete their report writing independently at once. We included the request in our tests to prevent the participants (especially group M) from copying and pasting perfunctorily without an intention to construct knowledge. In other words, it was necessary to make this assignment more realistic based on the following assumptions about investigative report writing:

- Copying and pasting text requires careful reading so that students can choose the text they wish to include in their reports. This assumption is based on the selection-to-read behavior that selects the text that students tend to read ${ }^{(23)}$.

- Careful reading will lead to information memorization.

(1) Group M

Group M participants were forced to use mouse operations to copy and paste expository text for the 
"Causes" subtopic. In addition, they could selectively copy and paste other expository text within the designated page and edit (modify) the text as necessary.

(2) Group T

Group T participants were forced to type the expository text verbatim into their reports. In addition, they could selectively type other expository text from the designated page and edit the text as necessary.

The following scoring method was explained in advance: "Students will receive a passing mark if they complete the forced copy-and-paste task. If they refine their report with other expository text, they will receive a moderate additional mark." The refinement was the unforced task, which was expected to encourage careful reading and was performed after the forced task. The students had one week to complete and submit the assignment.

\subsubsection{Recall Test}

Each year, the participants were given a 10-minute recall test without prior notice at the beginning of the class after different intervals from the submission deadline. The recall test was comprised of 10 fill-in-theblank questions about the expository text in the "Causes" subtopic. Appendix 1 shows the recall test (in Japanese). The blanks represent keywords in the expository text (e.g., eutrophication and plankton). The recall test was scored on a scale of 1-10, where 10 was a perfect score. The recall test was the same over the fiveyear period. The expository text changed slightly but the essential content did not change.

\subsubsection{Report Writing Time and Added Characters}

We recorded participant report writing time and counted the added characters because the copy-andpaste methods could influence aspects other than the recall test score.

The participants measured the time (minutes) they spent writing their report and included the total time in their reports. We counted the number of characters in other expository text that participants added (and edited) in their report.

\subsubsection{Questionnaire}

Immediately after the recall test, the participants answered a yes-no question regarding compliance with the forced task. Participants also answered the following questionnaire (Five-point Likert scale: 1=strongly disagree, $2=$ disagree, $3=$ neutral, $4=$ agree, $5=$ strongly agree).
(Q1) I surely understood the content of the expository text (the causes of red tide) that I copied and pasted [for group $\mathrm{M}$ ] or typed [for group T].

(Q2) I wrote my report effectively by copying and pasting [for group $\mathrm{M}$ ] or typing [for group T].

(Q3) I wrote my report efficiently by copying and pasting [for group $\mathrm{M}$ ] or typing [for group T].

(Q4) I did not feel that copying and pasting [for group $\mathrm{M}$ ] or typing [for group T] was a burden.

(Q5) I became interested in red tide through the report writing.

\subsection{Results}

Only participants who submitted their report before the deadline and took the recall test were compared. It should be noted that the number of participants in groups $\mathrm{M}$ and $\mathrm{T}$ differed. All participants confirmed that they had complied with their forced copy-and-paste task. Table 1 shows the final composition of the groups, i.e., the final number of participants, the mean remaining time (minutes) from report submission to the recall test, and the $p$-values of a two-tailed $t$-test of the mean remaining time for each year. Between the two groups within each year, no significant difference in the mean remaining time to take the recall test could be confirmed.

\subsubsection{Recall Test}

We scored the recall test by assigning 0 (incorrect) or 1 (correct) for each blank. It should be noted that minor mistakes (e.g., typos caused by similar kanji characters) were scored as correct. Then, we compared the mean score of the two groups within each year assuming a normal distribution and homoscedasticity in the general populations. We used a two-tailed $t$-test rather

Table 2. Test Scores.

\begin{tabular}{|c|c|c|c|c|c|c|}
\hline \multirow{2}{*}{ Year } & \multirow{2}{*}{$\begin{array}{c}\text { Interval } \\
\text { (days) }\end{array}$} & \multicolumn{2}{|c|}{ Group M } & \multicolumn{2}{c|}{ Group T } & \multirow{2}{*}{$\begin{array}{c}p \\
(t \text {-test })\end{array}$} \\
\cline { 3 - 6 } & Mean & S.D. & Mean & S.D. & - \\
\hline 2010 & 0 & 2.75 & 2.18 & 5.44 & 2.60 & $0.036^{*}$ \\
\hline 2011 & 4 & 2.88 & 2.14 & 6.91 & 2.05 & $3.5 \times 10^{-4 * *}$ \\
\hline 2012 & 14 & 0.42 & 0.53 & 3.0 & 1.19 & $1.6 \times 10^{-4 * *}$ \\
\hline 2013 & 35 & 1.75 & 1.16 & 3.25 & 1.50 & 0.083 \\
\hline 2014 & 21 & 3.57 & 1.61 & 4.07 & 2.05 & 0.582 \\
\hline
\end{tabular}

$* p<0.05, * * p<0.01$ 
Table 3. Report Writing Time (Minutes).

\begin{tabular}{|l|l|c|c|c|c|c|}
\hline \multirow{2}{*}{ Year } & \multirow{2}{*}{ Participant } & \multicolumn{2}{|c|}{ Group M } & \multicolumn{2}{|c|}{ Group T } & \multirow{2}{*}{$p$} \\
\cline { 3 - 6 } & & Med. & M.R. & Med. & M.R. & \\
\hline \multirow{2}{*}{2010} & All & 7 & 7.00 & 10 & 10.77 & 0.132 \\
\cline { 2 - 7 } & Passing & 9 & 5.20 & 10 & 8.77 & 0.137 \\
\hline \multirow{2}{*}{2011} & All & 5 & 7.27 & 9 & 13.79 & $0.018^{*}$ \\
\cline { 2 - 7 } & Passing & 5 & 6.35 & 9 & 12.12 & $0.033^{*}$ \\
\hline \multirow{2}{*}{2012} & All & 8 & 6.71 & 9 & 9.12 & 0.323 \\
\cline { 2 - 7 } & Passing & 5.5 & 6.00 & 8 & 7.85 & 0.428 \\
\hline \multirow{2}{*}{2013} & All & 2.5 & 4.62 & 15 & 10.25 & $0.013^{*}$ \\
\cline { 2 - 7 } & Passing & 2 & 4.00 & 15 & 9.50 & $0.010^{*}$ \\
\hline \multirow{2}{*}{2014} & All & 15 & 8.71 & 16 & 11.46 & 0.339 \\
\cline { 2 - 6 } & Passing & 15.5 & 6.30 & 10 & 10.12 & 0.168 \\
\hline
\end{tabular}

All=All participants

Passing=Participants who performed only the forced task and obtained a passing mark.

Med. $=$ Median, M.R. $=$ Mean Rank, ${ }^{*} p<0.05,{ }^{*} * p<0.01$

than ANOVA within each year because we assumed that the intervals could influence the mean scores among years. Table 2 shows the mean scores, standard deviations, and $p$-values of the $t$-test.

In all years, the mean scores of group $\mathrm{T}$ were higher than those of group M. The $t$-test results differed at a significance level of $1 \%$ for 2011 and 2012. In addition, a significant difference was observed at the $5 \%$ level in 2010. No significant differences could be confirmed for 2013 and 2014.

\subsubsection{Report Writing Time and Added Char- acters}

We employed nonparametric statistics to compare the report writing time of the two groups for each year because a normal distribution in and homoscedasticity between the two groups within each year were not confirmed. Table 3 shows the medians, mean ranks, and p-values of the Mann-Whitney $U$ test entailing classification of participants as "all participants" and "passing participants." Passing participants performed only the forced task and obtained a passing mark. We observed that the medians of group $\mathrm{T}$ were higher than those of group $\mathrm{M}$, regardless of the classification. The results of the test showed a significant difference at the 5\% level for 2011 and 2013. No significant differences could be confirmed for 2010, 2012, and 2014. In group M, the
Table 4. Added Characters.

\begin{tabular}{|c|c|c|c|c|}
\hline \multirow{2}{*}{ Year } & \multicolumn{2}{|c|}{ Group M } & \multicolumn{2}{|c|}{ Group T } \\
\hline & $N$ & NumChar & $N$ & NumChar \\
\hline \multirow{3}{*}{2010} & \multirow{3}{*}{3} & 40 & \multirow{3}{*}{0} & \multirow{3}{*}{ - } \\
\hline & & 188 & & \\
\hline & & 1,394 & & \\
\hline \multirow{2}{*}{2011} & \multirow{2}{*}{2} & 155 & \multirow{2}{*}{0} & \multirow{2}{*}{ - } \\
\hline & & 815 & & \\
\hline 2012 & 1 & 45 & 1 & 1,380 \\
\hline 2013 & 1 & 70 & 0 & - \\
\hline \multirow{2}{*}{2014} & \multirow{2}{*}{2} & 73 & \multirow{2}{*}{1} & \multirow{2}{*}{71} \\
\hline & & 589 & & \\
\hline
\end{tabular}

NumChar=Number of added characters for each participant

shortest report writing time was one minute and the longest was 40 minutes. In group $\mathrm{T}$, the shortest time was five minutes and the longest was 60 minutes.

Table 4 shows the number of participants who added other expository text and the numbers of added characters. Except for 2012, more participants in group $\mathrm{M}$ added other expository text than participants in group $\mathrm{T}$.

\subsubsection{Questionnaire}

Table 5 shows the medians, mean ranks, and p-values of the Mann-Whitney $U$ test (two-tailed test) for the questionnaire results for each year. For Q1, the test results showed significant differences at the 1 or $5 \%$ level for all years. For Q2, the test results showed significant differences at the 1 or $5 \%$ level for all years except 2010. For Q3, the test results showed significant differences at the 1 or $5 \%$ level for 2010, 2013, and 2014. For Q4, the test results showed significant differences at the 1 or $5 \%$ level for all years except 2012 . For Q5, the test results showed a significant difference for only 2010 .

\subsection{Considerations}

In this section, we consider the results separately and then comprehensively.

\subsubsection{Recall Test}

Comparative results indicate that the typing-based copy-and-paste method is more effective than the mouse-based method relative to information memorization. However, these mean scores become increasingly similar with an increase in the interval between report 
Table 5. Questionnaire Results.

\begin{tabular}{|c|c|c|c|c|c|c|c|c|c|c|c|c|c|c|c|}
\hline & \multicolumn{5}{|c|}{2010} & \multicolumn{5}{|c|}{2011} & \multicolumn{5}{|c|}{2012} \\
\hline & \multicolumn{2}{|c|}{ Group M } & \multicolumn{2}{|c|}{ Group T } & \multirow{2}{*}{$p$} & \multicolumn{2}{|c|}{ Group M } & \multicolumn{2}{|c|}{ Group T } & \multirow{2}{*}{$p$} & \multicolumn{2}{|c|}{ Group M } & \multicolumn{2}{|c|}{ Group T } & \multirow{2}{*}{$p$} \\
\hline & Med. & $M . R$. & Med. & $M . R$ & & Med. & M.R. & Med. & $M . R$ & & Med. & $M . R$. & Med. & $M . R$ & \\
\hline Q1 & 2 & 6.56 & 2 & 11.16 & $0.045^{*}$ & 2 & 6.50 & 3 & 14.37 & $0.002 * *$ & 1 & 4.71 & 2 & 10.28 & $0.007 * *$ \\
\hline Q2 & 2 & 7.37 & 2 & 10.44 & 0.199 & 2 & 6.50 & 3.5 & 14.37 & $0.003 * *$ & 2 & 5.21 & 2 & 9.78 & $0.036^{*}$ \\
\hline Q3 & 4.5 & 13.00 & 2 & 5.44 & $<0.001 * *$ & 4 & 13.11 & 3 & 9.41 & 0.166 & 4 & 8.42 & 3 & 6.57 & 0.428 \\
\hline Q4 & 5 & 11.75 & 2.77 & 6.55 & $0.029^{*}$ & 4 & 14.22 & 3 & 8.58 & $0.035^{*}$ & 5 & 8.57 & 4 & 6.42 & 0.343 \\
\hline \multirow[t]{4}{*}{ Q5 } & 1.5 & 6.25 & 4 & 11.44 & $0.030^{*}$ & 2 & 10.00 & 3 & 11.75 & 0.530 & 2 & 6.00 & 2 & 9.00 & 0.176 \\
\hline & \multicolumn{5}{|c|}{2013} & \multicolumn{5}{|c|}{2014} & & & & & \\
\hline & \multicolumn{2}{|c|}{ Group M } & \multicolumn{2}{|c|}{ Group $\mathrm{T}$} & \multirow{2}{*}{$p$} & \multicolumn{2}{|c|}{ Group M } & \multicolumn{2}{|c|}{ Group $\mathrm{T}$} & \multirow{2}{*}{$p$} & & & & & \\
\hline & Med. & $M . R$. & Med. & $M . R$ & & Med. & M.R. & Med. & $M . R$ & & & & & & \\
\hline Q1 & 1 & 5.00 & 2.5 & 9.50 & $0.028^{*}$ & 1 & 5.57 & 3 & 13.15 & $0.005^{* *}$ & & & & & \\
\hline Q2 & 1 & 4.81 & 4 & 9.87 & $0.011 *$ & 1 & 5.21 & 4 & 13.34 & $0.002 * *$ & & & & & \\
\hline Q3 & 4.5 & 8.18 & 2 & 3.12 & $0.023^{*}$ & 4 & 14.92 & 2 & 8.11 & $0.013 *$ & & & & & \\
\hline Q4 & 5 & 8.31 & 2 & 2.87 & $0.011^{*}$ & 4 & 15.07 & 2 & 8.03 & $0.008 * *$ & & & & & \\
\hline Q5 & 2 & 6.93 & 1.5 & 5.62 & 0.593 & 2 & 8.00 & 3 & 11.84 & 0.164 & & & & & \\
\hline
\end{tabular}

Med. $=$ Median, M.R. $=$ Mean Rank, $* p<0.05, * * p<0.01$

submission and the recall test. Thus, students forget a similar amount of memorized information with time regardless of the method that they use. Although comparing participants in different years is not justifiable, we think that the typing-based method does not necessarily stabilize memorized information as long-term memory. In general, to stabilize memorized information, students may have to perform memory maintenance activities (e.g., rehearsal). In addition, it may be important to shift from information memorization to knowledge construction. With regard to our investigative report writing model, students should perform information comparison and knowledge application after information memorization.

\subsubsection{Report Writing Time and Added Characters}

We assumed that group $\mathrm{T}$ would take more time to write the report than group $\mathrm{M}$ because the typing-based copy-and-paste method would have a higher burden than the mouse-based method. The effects of the typingbased method, i.e., information memorization enhanced by the typing burden, seem to be reflected in the mean test scores. However, the report writing time and the mean test score for each participant were poorly correlated. For participants who engaged only in the forced task, the correlation coefficients were 0.007 and -0.203 for groups $\mathrm{M}$ and $\mathrm{T}$, respectively. These correlations may be due to particular participant characteristics, such as typing skills and ability to concentrate. We also found that group $\mathrm{M}$ took more time to write the report than expected. This may be because we asked the participants to read the expository text carefully. If careful reading of the information is accompanied by the mouse-based method, students may memorize the information to a certain extent, which can further be used to construct knowledge.

Compared to group $\mathrm{T}$, we think that group $\mathrm{M}$ participants had a lower burden and therefore were motivated to deal with the additional task (copying and pasting other expository text). However, there were large variations in the number of added characters. This may have been caused by particular participant characteristics (e.g., interest in the topic, available time to write the report, and motivation to obtain a good mark).

\subsubsection{Questionnaire}

Although all participants were required to read the 
expository text carefully, group T participants tended to be surer of their understanding compared to group $\mathrm{M}$. This tendency seems to be reflected in the recall test scores. The typing-based method appears to be more effective than the mouse-based method for investigative report writing. This may indicate that participants tacitly felt that an easier method, i.e., a less burdensome method, is not preferable for investigative report writing. The results for groups $\mathrm{M}$ and $\mathrm{T}$ indicate that there may be a trade-off between effectiveness and efficiency. Regardless of method, participant interest in the report topic did not change. This may indicate that interest, which relates to learning motivation, is not affected by the copy-and-paste method.

\subsubsection{Overall Evaluation}

We placed heavy weight on the recall test scores to clarify the effects of copy-and-paste methods. Group T obtained better scores than group $\mathrm{M}$ in all years; the results were significantly better for three of the five years. Overall, from the above results and considerations, we consider that the typing-based method imposes a burden and decreases efficiency; however, it is more effective for information memorization than the mouse-based method. We expect that, compared to the mouse-based method, the typing-based method can contribute to effective knowledge construction that entails information memorization as the initial activity in investigative report writing.

\section{Conclusion}

This paper has described comparative experiments with mouse-based and typing-based copy-and-paste methods. The experimental results indicated that the typing-based method is more effective for information memorization in investigative report writing using the web as an information source (i.e., recalling text in web pages).

In our experiments, we did not strictly monitor and control participant report writing (e.g., styles and tools). For example, they tracked and declared their report writing time. In addition, report writing characteristics varied among different participants (e.g., report writing time and number of added characters). We note that the experiments had limitations. The experimental conditions lacked coherence and the results may not have high reproducibility. In the future, we would like to conduct additional experiments with more controlled and unified conditions while clarifying the cognitive processes inherent in the copy-and-paste methods. In addition, we would like to examine the validity of the investigative report writing model to verify how information memorization leads to knowledge construction.

Many people (e.g., university lecturers) may be able to predict the experimental results. However, we think that the results provide a new insight into how investigative reports written using the web as an information source should be evaluated. Even if students submit reports that contain copy-and-pasted text, the students may have memorized information and constructed knowledge about the given topic. If it is difficult to superficially assess whether text is copied and pasted by mouse-based or typing-based methods, such reports should not be disallowed (i.e., given a low score) if the information sources are cited properly.

These two copy-and-paste methods have advantages and disadvantages, (e.g., effectiveness and efficiency). We believe that students should use the two methods tactfully depending on the phases of investigative report writing such that they can write high-quality reports without web page plagiarism, i.e., effectively and efficiently construct knowledge from the web.

\section{Appendix 1}

[Question] 以下の文章の空白に適切な用語を書き入れよ. 赤潮の発生要因

水系の ( $\mathrm{A}$ ： 化) が主な原因とされる ( $\rightarrow$ 栄養塩). 従来, 合成洗剤に含まれている（B：酸塩）が問題視されたが, 近年では栄養塩の供給側の問題に加えて, 塩に対する浄化 側の作用低下の一因として，護岸工事による（C：）の 減少が問題視されている。 また，（D：）業の発達によ り, <D > 生命体の老廃物, 死骸による塩の過剰供給を指 摘する研究者も多い. $<\mathrm{C}>$ に住むアサリなどの生物は, そこに棲む微生物や（E：）等を䬣として取り込み海洋 への栄養塩や有機物の流入を食い止めるという, いわば自 然の（F：）の役割を果たしてきた. しかし, 護岸工 事などにより $<\mathrm{C}>$ が大幅に減少し湾内の $<\mathrm{A}>$ が進行. こ れを一因として $<$ E > が大量発生すると考えられている. (G：＼cjkstart湾）の干拓事業に扔ては, 干拓に伴う経済的な利 害関係と並び, 有明海での赤潮発生との因果関係が議論され ている. 有明海の他, 日本においては $(\mathrm{H}$ ： 海), (I : 湾), 伊勢湾, 大阪湾などの (J : 部) で発生 が多く報告されている。

[Correct Answers]（A：富栄養化）( $B$ : リン酸塩）( $C$ : 干潟） $(D$ :養殖 $)(E:$ プランクトン) ( $F$ : 浄化槽 $)(G$ : 諫早湾 $)(H$ : 瀬戸内海 $)(I$ : 東京湾 $)(J$ ：内湾部 $)$ 


\section{Acknowledgements}

This study was supported in part by the Grant-in-Aid for Scientific Research (B) No. 26282047 from the Japan Society for the Promotion of Science.

\section{References}

(1) Howard, R. M.: "Understanding 'Internet Plagiarism", Computers and Composition, Vol. 24, pp. 3-15 (2007).

(2) Dalal, N.: "Responding to Plagiarism Using Reflective Means", International J. for Educational Integrity, Vol. 11, No. 4 (2015).

(3) Marsh, B.: "Turnitin.com and the Scriptural Enterprise of Plagiarism Detection", Computers and Composition, Vol. 21, pp. 427-438 (2004).

(4) Vie, S.: "A Pedagogy of Resistance Toward Plagiarism Detection Technologies", Computers and Composition, Vol. 30, pp. 3-15 (2013).

(5) Mitsuhara, H., Shishibori, M. and Kashihara, A.: "Preventing Web Page Plagiarism in Investigative Report Writing", Proc. of 7th Intl. Conf. on the Applications of Digital Information and Web Technologies (ICADIWT2016), pp. 162-171 (2016).

(6) Mitsuhara, H., Shishibori, M. and Kashihara, A.: "Investigative Report Writing Support System for Effective Knowledge Construction from the Web", IEICE Transactions on Information and Systems, Vol. E101-D, No. 4 (accepted) (2018).

(7) Kulathuramaiyer, K. and Maurer, H.: "Coping with the Copy-Paste-Syndrome", Proc. of World Conference on E-Learning in Corporate, Government, Healthcare, and Higher Education 2007 (E-Learn2007), pp. 1072-1079 (2007).

(8) Gehlen-Baum, V. and Weinberger, A.: "Notebook or Facebook? How Students Actually Use Mobile Devices in Large Lectures", Proc. of 7th European Conf. of Technology Enhanced Learning (EC-TEL2012), pp. 103112 (2012).

(9) Mueller, P. A. and Oppenheimer, D. M.: “The Pen Is Mightier than the Keyboard: Advantages of Longhand Over Laptop Note Taking”, Psychological Science, Vol 25, Issue 6, pp. 1-10 (2014).

(10) Bui, D. C., Myerson, J. and Hale, S.: "Note-Taking with Computers: Exploring Alternative Strategies for Improved Recall", J. of Educational Psychology, Vol. 105, No. 2, pp. 299-309 (2013).

(11) Hosoi, K., Mitsuhara, H. and Yano, Y.: "Fundamental Support and Reflection Support for Report Writing from
Web", Workshop Proc. of the 18th Intl. Conf. on Computers in Education (ICCE2010), pp. 117-124 (2010).

(12) Mitsuhara, H., Kanenishi, K. and Yano, Y.: "Bookmark Sharing for Learning Path Navigation Provided as Web Search Support", The J. of Information and Systems in Education, Vol. 5, No. 1, pp. 55-65 (2006).

(13) Piolat, A., Olive, T. and Kellogg, R. T.: "Cognitive Effort during Note Taking”, Applied Cognitive Psychology, Vol. 19, Issue 3, pp. 291-312 (2005).

(14) Stacy, E. M. and Cain, J.: "Note-taking and Handouts in the Digital Age", American J. of Pharmaceutical Education, Vol. 79, No. 7, Article 107 (2015).

(15) King, A.: "Comparison of Self-Questioning, Summarizing, and Notetaking-Review as Strategies for Learning from Lectures", American Educational Research J., Vol. 29, No. 2, pp. 303-323 (1992).

(16) Wei, F.-Y. F., Wang, Y. K. and Fass, W.: "An Experimental Study of Online Chatting and Notetaking Techniques on College Students' Cognitive Learning from a Lecture", Computers in Human Behavior, Vol. 34, pp. 148-156 (2014).

(17) Beck, K. M.: "Note Taking Effectiveness in the Modern Classroom", The Compass, Vol. 1, Issue 1, Article 9 (2014).

(18) Reimer, Y. J., Brimhall, E., Cao, C. et al.: "Empirical User Studies Inform the Design of an E-Notetaking and Information Assimilation System for Students in Higher Education", Computers \& Education, Vol. 52, Issue 4, pp. 893-913 (2009).

(19) Katayama A. D., Shambaugh, R. N. and Doctor, T.: "Promoting Knowledge Transfer with Electronic Note Taking”, Teaching of Psychology, Vol. 32, No. 2, pp. 129-131 (2005).

(20) Igo, L. B., Bruning, R. and McCrudden, M. T.: "Exploring Differences in Students' Copy-and-Paste Decision Making and Processing: A Mixed-Methods Study", J. of Educational Psychology, Vol. 97, No. 1, pp. 103-116 (2005).

(21) Bauer, A. and Koedinger, K. R.: "Pasting and Encoding: Note-taking in Online Courses", Proc. of 6th IEEE International Conference on Advanced Learning Technologies (ICALT2006), pp. 789-793 (2006).

(22) Bauer, A. and Koedinger, K. R.: "Selection-based Notetaking Applications", Proc. of 25th SIGCHI Conference on Human Factors in Computing Systems (CHI2007), pp. 981-990 (2007).

(23) Bauer, A. and Koedinger, K. R.: "Note-taking, Selecting, 
and Choice: Designing Interfaces that Encourage Smaller Selections", Proc. of the 8th ACM/IEEE-CS Joint

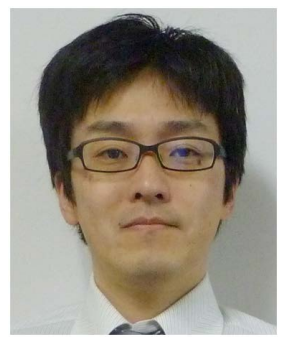

disaster education.

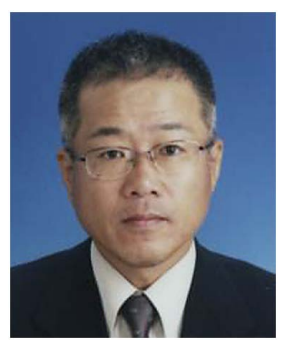

Masami Shishibori received his B.S. Degree in 1991, his M.S. Degree in 1993 and Ph.D. Degree in 1997, from Tokushima University, Japan. He is currently a Professor in the Department of Computer Science, Graduate School of Technology, Industrial and Social Sciences, Tokushima University, Japan. His research interests include multimedia processing, information retrieval, and natural language processing.
Conference on Digital Libraries (JCDL2008), pp. 397406 (2008).

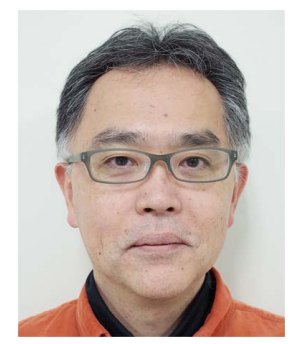

Akihiro Kashihara received his B.S. and M.S. in Computer Science and System Engineering from Tokushima University in 1987 and 1989, and his Ph.D. in Information and Computer Science from Osaka University in 1992. He was an Assistant and then Associate Professor of the Institute of Scientific and Industrial Research in Osaka University from 1992 to 2004 . He is currently a Professor in the Graduate School of Informatics and Engineering, The University of Electro-Communications. His main research interests lie in modeling of learning processes and designing intelligent learning environments. 